\title{
Article \\ Complex Exercise Improves Anti-Inflammatory and Anabolic Effects in Osteoarthritis-Induced Sarcopenia in Elderly Women
}

\author{
Jaeyong Park ${ }^{1}$, Jongjin Bae ${ }^{2}$ and Jungchul Lee ${ }^{3, *(D)}$ \\ 1 Institute of Sports Health Science, Sunmoon University, 70, Sunmoon-ro 221 beon-gil, Tangjeong-Myeon, \\ Asan-si 31460, Korea; 2006076@sunmoon.ac.kr \\ 2 Data Center, Hannam University, 70 Hannamro, Daedeok-Gu, Daejeon 34430, Korea; bjj008@hnu.kr \\ 3 Department of Exercise Prescription, Dongshin University, 185, Geonjae-Ro, Naju, Jeonnam 58245, Korea \\ * Correspondence: channel365@dsu.ac.kr; Tel.: +82-10-7609-8195
}

Citation: Park, J.; Bae, J.; Lee, J. Complex Exercise Improves

Anti-Inflammatory and Anabolic Effects in Osteoarthritis-Induced Sarcopenia in Elderly Women. Healthcare 2021, 9, 711. https:// doi.org/10.3390/healthcare9060711

Academic Editors:

Daniela Figueiredo and Oscar Ribeiro

Received: 19 May 2021

Accepted: 8 June 2021

Published: 10 June 2021

Publisher's Note: MDPI stays neutral with regard to jurisdictional claims in published maps and institutional affiliations.

Copyright: () 2021 by the authors. Licensee MDPI, Basel, Switzerland. This article is an open access article distributed under the terms and conditions of the Creative Commons Attribution (CC BY) license (https:// creativecommons.org/licenses/by/ $4.0 /)$.

\begin{abstract}
We investigated the effects of a 15-week complex exercise program on osteoarthritis and sarcopenia by analyzing anabolic effects and the impact on the activities of daily living (ADLs). Nineteen women aged $\geq 60$ years with sarcopenia (SEG, $n=9$ ) or diagnosed with osteoarthritis with sarcopenia (OSEG, $\mathrm{n}=10$ ) were enrolled and underwent an exercise program. Insulin-like growth factor 1 (IGF-1), irisin, myostatin, interleukin-10 (IL-10), and tumor necrosis factor alpha (TNF-a) levels were analyzed pre- and post-intervention. Thigh cross-sectional area (TCSA) was measured pre- and post-intervention via computed tomography. Western Ontario and McMaster Universities Osteoarthritis Index (WOMAC) and Short Physical Performance Battery (SPBB) were assessed preand post-interventions to assess ADL. There was a significant interaction effect between SEG and OSEG at the IGF-1 level post-intervention. Irisin increased and myostatin decreased post-intervention in both groups. IL-10 increased and TNF- $\alpha$ decreased post-intervention with a significant interaction effect in the OSEG group. TCSAs increased post-intervention in both groups. There was a significant interaction between the two groups. OSEG showed a greater WOMAC decrease and SPPB increase post-intervention, and there was a significant interaction effect. Combined exercise may be effective in improving biochemical factors, anabolic effects, and ADL in elderly women with osteoarthritis and sarcopenia.
\end{abstract}

Keywords: sarcopenia; osteoarthritis; complex exercise; myokine; TCSA

\section{Introduction}

Sarcopenia is caused by the interaction of a variety of factors and pathways, such as environmental factors, endocrine dysregulation, loss of motor neurons, activation of inflammatory pathways, and reduced satellite cell counts [1]. Inflammatory markers are involved in age-related loss of muscle mass. Elevated TNF- $\alpha$ levels increase the anabolic effects on muscles by inhibiting the rapamycin signaling, and inflammatory cytokines have an antagonistic effect on muscle synthesis by diminishing circulating and muscular insulin growth factor (IGF)-1 levels [2]. Interleukin (IL)-10 concentration in the blood is known to inhibit tumor necrosis factor (TNF)- $\alpha$, and increases in cytokine levels as a result of aging are believed to be closely associated with sarcopenia [3]. Myostatin (Mstn), an extracellular cytokine, is a transforming growth factor (TGF) that hinders the regulation of skeletal muscle mass and growth. Mstn is exclusively expressed in skeletal muscles, where it inhibits the differentiation and proliferation of myoblasts through an antagonistic effect on IGF-1 or follistatin [4]. In addition, Mstn is associated with aging. Yarasheski et al. [5] reported that physically frail elderly women showed the highest elevation of serum Mstn levels and that elevation of Mstn levels is negatively correlated with skeletal muscle mass; however, aging-related changes in circulating or muscle Mstn-immunoreactive protein levels or Mstn mRNA have not been proven [6]. Further research is needed to address the contradictory results pertaining to the relationship between Mstn and aging. 
Irisin, a myokine associated with increased muscle mass, is significantly and positively correlated with skeletal muscle mass and strength; therefore, it has been proposed as a potential biomarker of sarcopenia and muscular impairment [7]. Regular exercise has been reported to increase irisin levels and inhibit Mstn, which hinders muscle growth [8]. Ultimately, achieving sufficient muscle mass is important to increase muscle strength, as muscle mass and strength are positively correlated [9].

Studies on the effects of exercise on increasing muscle mass have reported that aerobic exercise facilitates skeletal muscle growth as well as mitochondrial ATP production and improves aerobic capacity, metabolic regulation, and cardiovascular functions [10]. In other words, aerobic exercise restores mitochondrial metabolism, reduces the expression of catabolic genes, and increases muscle protein synthesis [10-12]. In addition, exercise is helpful in maintaining the expression of autophagy proteins and may also upregulate the expression of autophagy-related proteins in skeletal muscle [13]. Furthermore, aerobic exercise has been proposed to regulate Mtsn mRNA expression [14].

In the elderly, strength training stimulates growth hormone secretion that promotes muscle cell growth and muscle strength [15]. Strength training also contributes to an increase in bone density [16]. In particular, resistance exercise can restore a significant portion of lost muscle function and delay deterioration of muscle structure associated with aging [17]. In addition, the cross-sectional area of the muscles of the elderly who perform resistance exercise has been reported to increase similarly to that of younger individuals [18].

Osteoarthritis (OA) accompanied by sarcopenia is a chronic disease in which gradual deterioration of joint cartilage causes subchondral damage and secondarily induces inflammation in other tissues, and ultimately impairs physical functioning [19].

Previous studies have shown that aging-induced sarcopenia is closely associated with OA $[20,21]$. The classic feature of OA is pathological inflammation, and cytokines, such as TNF- $\alpha$ and IL-6, play an important role in the destruction of cartilage [22]. Therefore, reducing TNF- $\alpha$ levels is crucial in treating chronic pain caused by OA.

Prolonged drug therapy to treat inflammation may likely lead to adverse reactions, such as infection, autoimmune diseases, and tumors [23]. However, exercise increases the secretion of the anti-inflammatory cytokine IL-10 and inhibits the production of proinflammatory cytokines, such as TNF- $\alpha$, without any adverse reactions [24].

Because cytokines characteristically expressed in sarcopenia may induce OA, it has been suggested that exercise may have protective effects on muscles. Resistance exercise, a classic exercise for OA, is an important intervention used to inhibit muscle loss by facilitating muscle protein synthesis and muscle growth. Regular resistance exercise enhances exercise performance by enlarging muscle fibers and increasing cross-sectional surface area, however it has been reported that there are limitations in promoting mitochondrial protein expression and improving functioning with resistance exercise alone in elderly individuals with sarcopenia [25]. Furthermore, simple resistance exercise may be less effective in older adults because of low levels of mammalian target of rapamycin (mTOR) signaling, which is involved in muscle protein synthesis [26].

Therefore, a single form of exercise is not an optimal therapeutic exercise intervention for aging-related sarcopenia. A balanced combined exercise program including both aerobic and resistance exercises should be recommended to improve aging-induced sarcopenia [27].

Therefore, this study aimed to investigate the therapeutic effects of a combined exercise program on sarcopenia and OA by analyzing its anabolic effects on muscles and activities of daily living (ADL).

\section{Materials and Methods}

\subsection{Subjects}

Elderly women aged $\geq 60$ years who resided in Asan-si were enrolled; of these, 19 women had sarcopenia, defined by muscle strength $\leq 20 \mathrm{~kg}$ based on grip strength [28]. The participants were divided into the no OA group (SEG, $n=9$ ) and a group diagnosed 
with OA (Kellgren-Lawrence Grade I or II) by an orthopedic surgeon (OSEG, $\mathrm{n}=10$ ). We excluded those with a history of musculoskeletal injury in the past 6 months, history of knee surgery or intra-articular steroid administration, and inability to ambulate independently. Before enrollment, subjects confirmed understanding of the purpose of the study and indicated willingness to participate, after being informed of the experimental procedures in detail. This study was approved by the institutional review board of Sunmoon University (SM-201908-045-1). The participants' physical characteristics are shown in Table 1.

Table 1. Physical characteristics of subjects.

\begin{tabular}{cccccc}
\hline Group & Age (Years) & Height $(\mathbf{c m})$ & Weight $\mathbf{( k g )}$ & \%Fat (\%) & SMM (kg) \\
\hline SEG $(\mathrm{n}=9)$ & $64.8 \pm 3.80$ & $153.9 \pm 4.22$ & $59.7 \pm 6.12$ & $33.6 \pm 5.01$ & $20.6 \pm 1.74$ \\
OSEG $(\mathrm{n}=10)$ & $66.6 \pm 3.98$ & $151.6 \pm 8.61$ & $58.0 \pm 11.53$ & $35.8 \pm 5.88$ & $20.3 \pm 4.41$ \\
\hline
\end{tabular}

Values are reported as mean \pm standard deviation (SD). SEG, sarcopenia exercise group; OSEG, osteoarthritis sarcopenia exercise group; SMM, skeletal muscle mass.

\subsection{Experimental Design}

The experimental procedure of this study is shown in Figure 1.

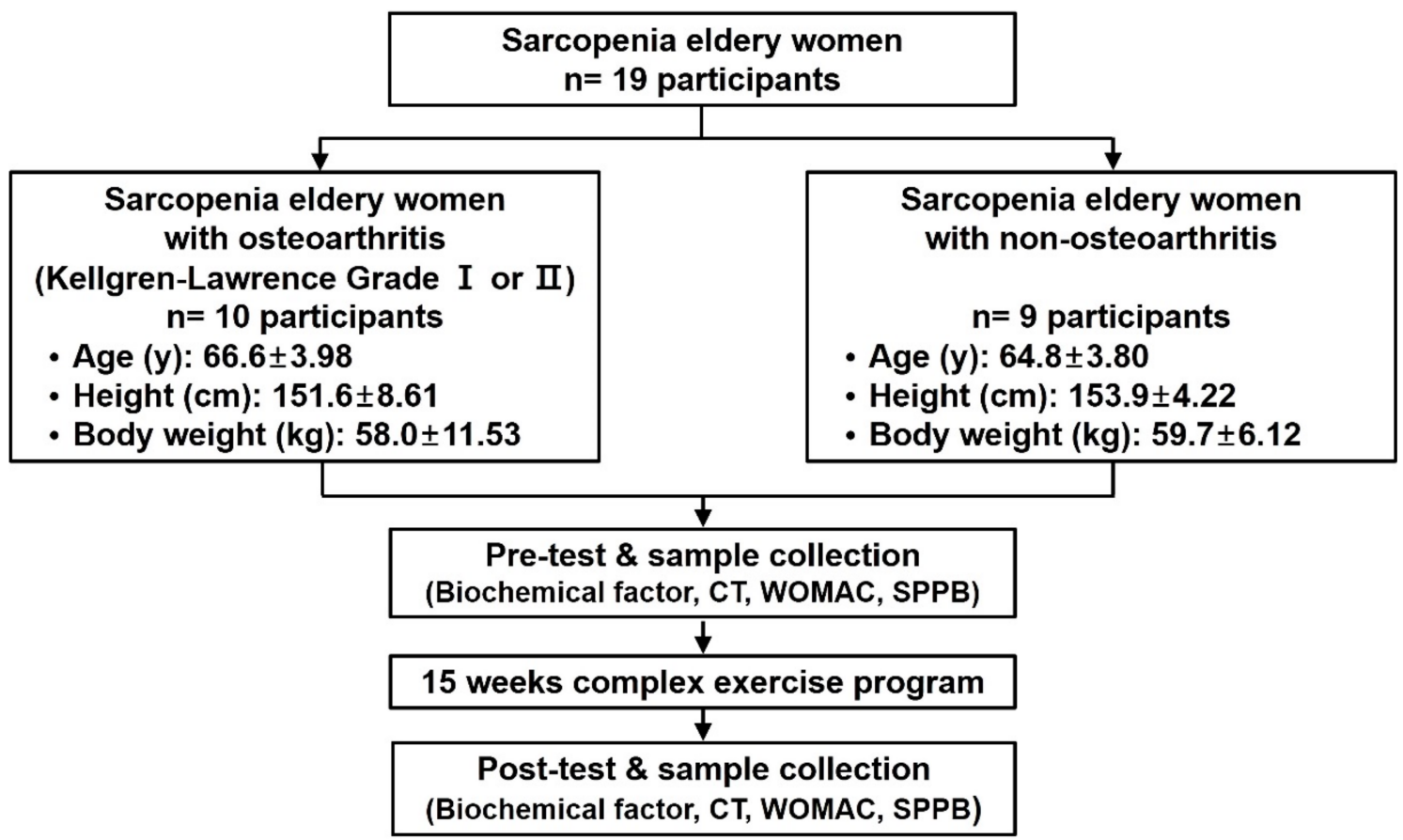

Figure 1. Inspection processes and procedures. WOMAC, Western Ontario and McMaster Universities Osteoarthritis Index; SPPB, Short Physical Performance Battery.

\subsection{Measurement of Cross-Sectional Area of the Thigh}

The anatomical cross-sectional area (CSA) of the quadriceps muscle was assessed by computed tomography (CT) scanning (Siemens, Munich, Germany), as described previously [29]. With the subject in the supine position, the right mid-thigh CSA was measured by $\mathrm{CT}$ at the midpoint from the inguinal crease to the proximal pole of the patella (Figure 2). Briefly, the scanning characteristics were as follows: $120 \mathrm{kV}, 300 \mathrm{~mA}$, rotation time of $0.75 \mathrm{~s}$, and field of view of $500 \mathrm{~mm}$. With the subjects lying supine, legs extended, and their feet secured, a 3-mm-thick axial image was taken $15-\mathrm{cm}$ proximal to the base of the patella. The muscle area of the right leg was selected between 0 and 100 Hounsfield units [30], after which the quadriceps muscle was manually traced using ImageJ software (version 1.45 d; National Institutes of Health, Bethesda, MD, USA) [31]. 


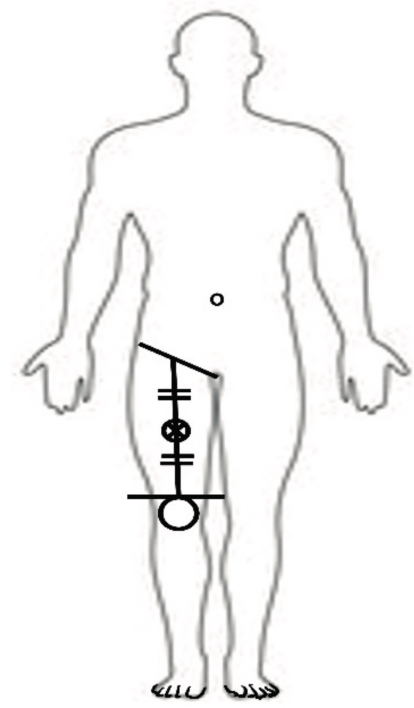

(a)

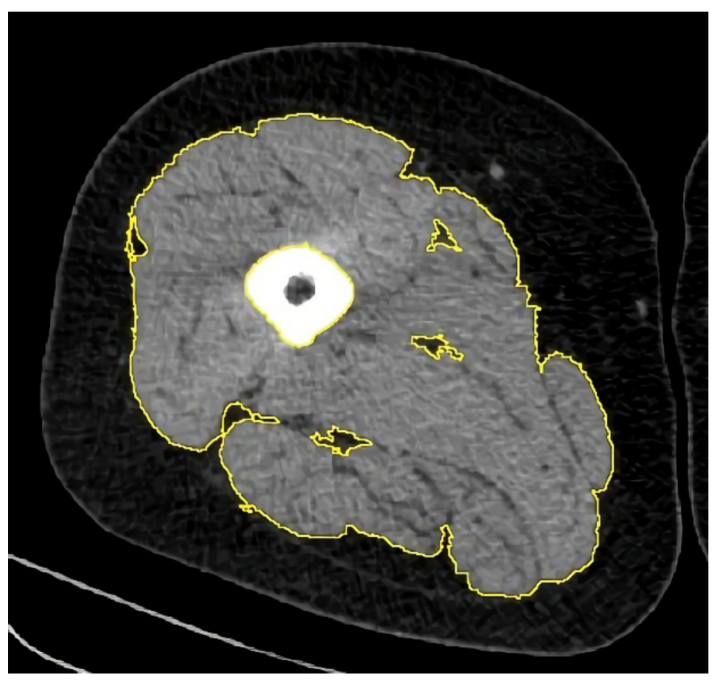

(b)

Figure 2. Cross-sectional muscle area (CSMA) determined by mid-thigh CT. (a) CSMA was measured at the midpoint from the inguinal crease to the proximal pole of the patella; (b) CSA of subcutaneous fat, intermuscular fat, and bone have been removed.

\subsection{Blood Sampling and Biochemical Analysis}

Blood samples were collected by a medical doctor from each participant after $12 \mathrm{~h}$ of fasting. The samples $(10 \mathrm{~mL})$ were centrifuged $\left(1000 \times g, 4{ }^{\circ} \mathrm{C}, 15 \mathrm{~min}\right)$ and the serum was aliquoted and stored at $-80^{\circ} \mathrm{C}$ for subsequent analysis. For the analysis of serum IGF-1, Mstn, TNF- $\alpha$, and IL-10, 50-, 50-, 50-, and 200- $\mu$ L of serum samples were analyzed using commercial enzyme-linked immunosorbent assay (ELISA) kits (R\&D Systems, Minneapolis, MN, USA). The lower limits of detection were $0.094 \mathrm{ng} / \mathrm{mL}, 31.3 \mathrm{pg} / \mathrm{mL}, 15.6 \mathrm{pg} / \mathrm{mL}$, and $7.8 \mathrm{pg} / \mathrm{mL}$, respectively. Irisin (in a $100-\mu \mathrm{L}$ of serum sample) was analyzed using a commercial kit (Aviscera Bioscience Inc., Santa Clara, CA, USA), with a lower limit of detection of $0.8 \mathrm{~mL}$. All factors were measured using an ELISA reader (Benchmark Plus Microplate Spectrophotometer, Bio-Rad Hercules, CA, USA) at $450 \mathrm{~nm}$. Values below this limit were assumed to be zero for the statistical analysis. The inter- and intra-assay coefficients of variance were $<10 \%$.

\subsection{Complex Exercise Program}

The 15-week complex exercise program supplemented Park and Song's [32] exercise program for the elderly and was conducted by a professional health and exercise instructor at a public health facility. The exercise program implemented in this study is shown in Tables 2 and 3 .

Table 2. The 15-week complex exercise program for elderly woman with sarcopenia and osteoarthritis.

\begin{tabular}{ccccc}
\hline Phase & Type & Exercise Contents & Time & Intensity/Frequency \\
\hline & Warm-up & Dynamic stretching & $10 \mathrm{~min}$ & 5 days/week \\
AP & Mat exercise & $30 \mathrm{~min}$ & 3 days/week \\
$(1-5$ & Work out & Chair exercise & & $40-50 \%$ HRR (RPE \\
weeks) & & Aerobic (walking) & $30 \mathrm{~min}$ & $11-12), 5$ days /week \\
& & Ctatic stretching & $10 \mathrm{~min}$ & 5 days/week \\
\hline
\end{tabular}


Table 2. Cont.

\begin{tabular}{|c|c|c|c|c|}
\hline Phase & Type & Exercise Contents & Time & Intensity/Frequency \\
\hline \multirow{3}{*}{$\begin{array}{c}\text { IP } \\
(6-10 \\
\text { weeks })\end{array}$} & Warm-up & Dynamic stretching & $10 \mathrm{~min}$ & 5 days/week \\
\hline & \multirow[t]{2}{*}{ Work out } & $\begin{array}{l}\text { Mat \& gym ball } \\
\text { exercise }\end{array}$ & $30 \mathrm{~min}$ & 3 days/week \\
\hline & & Aerobic (walking) & $30 \mathrm{~min}$ & $\begin{array}{l}50-60 \% \text { HRR (RPE } \\
12-13 \text { ), } 5 \text { days / week }\end{array}$ \\
\hline \multirow{4}{*}{$\begin{array}{c}\text { MP } \\
(11-15 \\
\text { weeks })\end{array}$} & $\begin{array}{l}\text { Cool down } \\
\text { Warm-up }\end{array}$ & $\begin{array}{l}\text { Static stretching } \\
\text { Dynamic stretching }\end{array}$ & $\begin{array}{l}10 \min \\
10 \min \end{array}$ & $\begin{array}{l}5 \text { days/week } \\
5 \text { days/week }\end{array}$ \\
\hline & \multirow[t]{2}{*}{ Work out } & $\begin{array}{l}\text { Mat \& gym ball } \\
\text { exercise }\end{array}$ & $30 \mathrm{~min}$ & 3 days/week \\
\hline & & Aerobic (walking) & $40 \mathrm{~min}$ & $\begin{array}{c}50-60 \% \text { HRR (RPE } \\
12-14 \text { ), } 5 \text { days/week }\end{array}$ \\
\hline & Cool down & Static stretching & $10 \mathrm{~min}$ & 5 days/week \\
\hline
\end{tabular}

Table 3. Details of the mat, chair, and gym ball exercises of the 15-week complex exercise program.

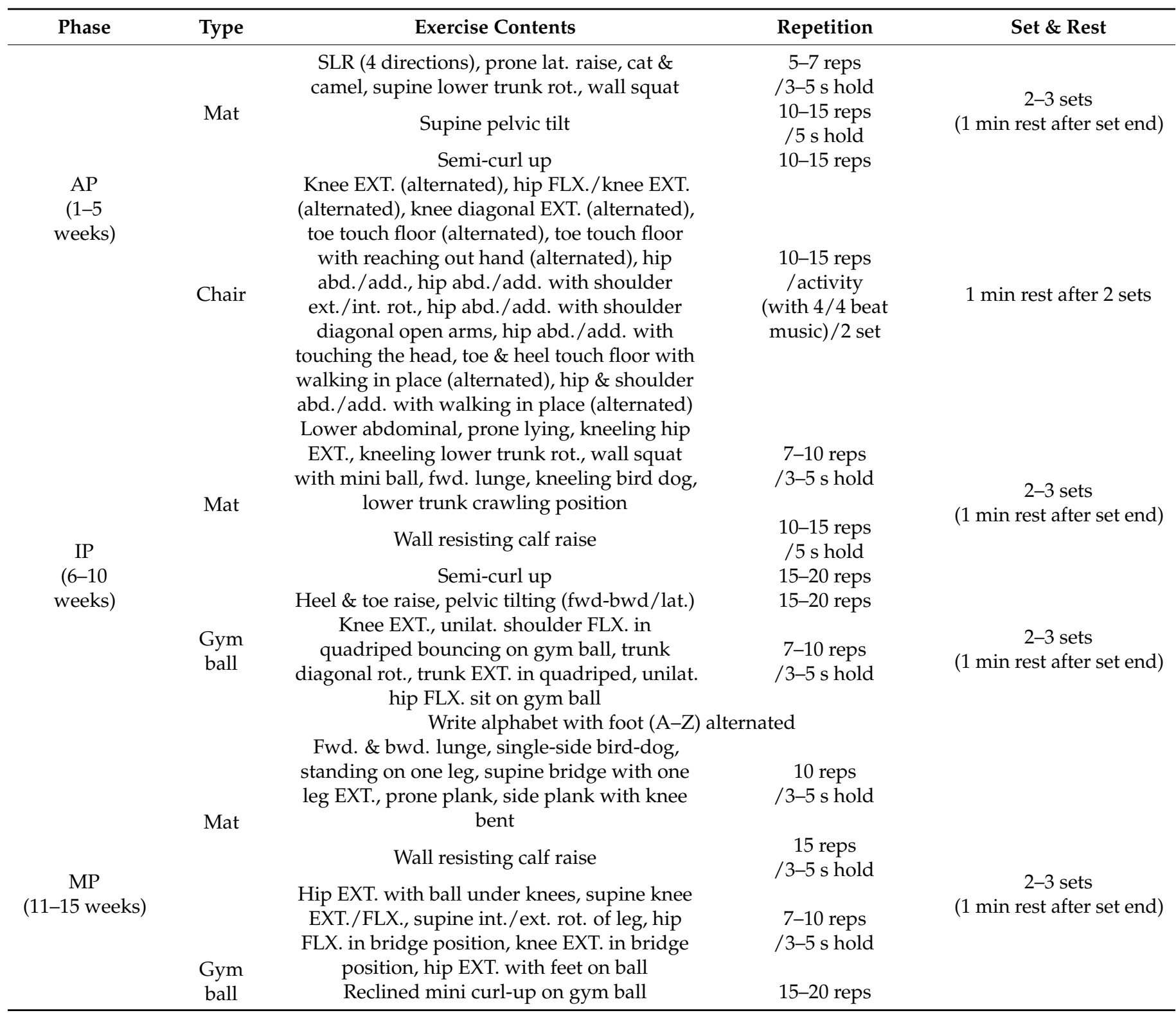

$\mathrm{AP}$, adaptation phase; IP, improvement phase; MP, maintenance phase; SLR, straight leg raise; EXT., extension; FLX., flexion; lat., lateral; abd., abduction; add., adduction; rot., rotation; int., internal; ext., external; fwd., forward; bwd., backward' unilat., unilateral. 


\subsection{Data Processing}

The mean and standard deviation (SD) of each study parameter were computed using IBM SPSS Statistics version 26 (IBM Corp., Armonk, NY, USA). The group and interaction effects for each variable were analyzed using two-way repeated measures ANOVA. Unpaired $t$-tests were performed as post-hoc analysis for differences between groups, and paired $t$-tests were performed for differences between time points. The statistical significance $(\alpha)$ was set at 0.05 .

\section{Results}

Table 4 shows the changes in serum myokines (IGF-1, irisin, Mstn, IL-10, and TNF- $\alpha$ ) before and after the intervention between the two groups.

Table 4. Serum myokine analysis.

\begin{tabular}{|c|c|c|c|c|c|}
\hline Variables & Group & Pre-Intervention & Post-Intervention & $\Delta$-Value & $t$-Value \\
\hline \multirow{4}{*}{ IGF-1 (ng/mL) } & OSEG & $111.17 \pm 28.18$ & $129.64 \pm 28.08$ & 18.5 & $-4.74^{* * *}$ \\
\hline & SEG & $106.99 \pm 20.99$ & $107.90 \pm 14.09$ & 0.19 & -0.89 \\
\hline & $t$-value & -0.36 & -2.13 & \multicolumn{2}{|c|}{ Group $\times$ Time $F(1,17)=12.22 * *$} \\
\hline & OSEG & $1.69 \pm 0.18$ & $2.38 \pm 0.38$ & 0.69 & $-6.99 * * *$ \\
\hline \multirow[t]{3}{*}{ Irisin $(\mathrm{ng} / \mathrm{mL})$} & SEG & $1.86 \pm 0.40$ & $2.64 \pm 0.79$ & 0.78 & $-4.15^{* *}$ \\
\hline & $t$-value & -1.20 & -0.93 & \multicolumn{2}{|c|}{ Group $\times$ Time $F(1,17)=0.20$} \\
\hline & OSEG & $1105.22 \pm 277.29$ & $775.60 \pm 183.35$ & -329.61 & $5.45^{* * *}$ \\
\hline \multirow[t]{3}{*}{ Mstn (pg/mL) } & SEG & $1006.19 \pm 234.35$ & $828.72 \pm 221.07$ & -177.46 & $3.30 * *$ \\
\hline & $t$-value & 0.84 & -0.57 & \multicolumn{2}{|c|}{ Group $\times$ Time $F(1,17)=3.47$} \\
\hline & OSEG & $101.93 \pm 40.83$ & $232.20 \pm 74.85$ & 130.26 & $-7.43^{* *}$ \\
\hline \multirow{3}{*}{ IL-10 (pg/mL) } & SEG & $166.68 \pm 58.71$ & $234.21 \pm 54.34$ & 67.52 & $-3.58^{* *}$ \\
\hline & $t$-value & $-2.82 *$ & -0.07 & \multicolumn{2}{|c|}{ Group $\times$ Time $F(1,17)=5.96 *$} \\
\hline & OSEG & $131.77 \pm 6.30$ & $119.95 \pm 7.49$ & -11.82 & $4.44^{* *}$ \\
\hline \multirow{2}{*}{$\mathrm{TNF}-\alpha(\mathrm{pg} / \mathrm{mL})$} & SEG & $129.72 \pm 4.33$ & $124.59 \pm 2.26$ & -5.13 & $3.56^{* *}$ \\
\hline & $t$-value & 0.82 & -1.78 & \multicolumn{2}{|c|}{ Group $\times$ Time $F(1,17)=4.59 *$} \\
\hline
\end{tabular}

Values are reported as mean \pm SD. OSEG, osteoarthritis sarcopenia exercise group; SEG, sarcopenia exercise group; IGF-1, insulin-like growth factor 1; Mstn, myostatin; TNF- $\alpha$, tumor necrosis factor alpha; SD, standard deviation. ${ }^{*} p<0.05 .{ }^{* *} p<0.01 .{ }^{* * *} p<0.001$.

IGF-1 significantly increased after exercise in the OSEG $(p<0.001)$. In particular, there was an interaction effect between the two groups $(p<0.01)$. In other words, while the two groups presented similar IGF-1 levels before the exercise, IGF-1 expression markedly increased in the OSEG after the exercise. Conversely, the SEG showed little change in IGF-1 levels. Irisin significantly increased after the intervention in both groups, with no significant differences between the two groups $(p<0.01)$. Mstn significantly decreased in both groups $(p<0.01)$. Although the interaction effect was not statistically significant, as OSEG showed a relatively high variability, the OSEG tended to show a greater reduction.

IL-10 levels increased by $67.52 \mathrm{pg} / \mathrm{mL}$ in the SEG, but increased by $130.26 \mathrm{pg} / \mathrm{mL}$ in the OSEG, from $101.93 \pm 40.83 \mathrm{pg} / \mathrm{mL}$ at baseline to $232.20 \pm 74.85 \mathrm{pg} / \mathrm{mL}$ after the intervention, confirming an interaction effect $(p<0.05)$. In other words, while the OSEG had relatively low levels of IL-10 compared to the SEG at baseline, the levels rose to a level similar to those of SEG after the intervention. There was a group and time interaction effect for TNF- $\alpha$, where the OSEG showed a statistically significantly greater reduction compared to the SEG $(p<0.05)$. In other words, TNF- $\alpha$, a characteristic biomarker, was reduced more dramatically in the OSEG.

Table 5 shows the changes in TCSA $\left(\mathrm{cm}^{2}\right)$ and ADL after the exercise program in both groups. 
Table 5. Cross-sectional area and physical activity ability analysis.

\begin{tabular}{|c|c|c|c|c|c|}
\hline Factor & Group & Pre & Post & $\Delta$-Value & $t$-Value \\
\hline \multirow{3}{*}{ L-TCSA $\left(\mathrm{cm}^{2}\right)$} & OSEG & $88.48 \pm 15.19$ & $94.52 \pm 14.70$ & 6.04 & $-8.23^{* * *}$ \\
\hline & SEG & $99.62 \pm 6.91$ & $110.42 \pm 6.04$ & 10.80 & $-6.36^{* * *}$ \\
\hline & $t$-value & -2.02 & $-3.02 * *$ & \multicolumn{2}{|c|}{ Group $\times$ Time $F(1,17)=7.12 *$} \\
\hline \multirow{3}{*}{$\mathrm{R}-\mathrm{TCSA}\left(\mathrm{cm}^{2}\right)$} & OSEG & $89.36 \pm 14.26$ & $93.06 \pm 16.36$ & 3.70 & $-3.27^{* *}$ \\
\hline & SEG & $102.44 \pm 11.21$ & $110.04 \pm 6.98$ & 7.61 & $-3.31 *$ \\
\hline & $t$-value & -2.20 & $-2.88^{* *}$ & \multicolumn{2}{|c|}{ Group $\times$ Time $F(1,17)=2.5$} \\
\hline \multirow{3}{*}{$\begin{array}{c}\text { WOMAC } \\
\text { (score) }\end{array}$} & OSEG & $61.70 \pm 17.493$ & $40.30 \pm 13.132$ & -21.40 & $6.24^{* * *}$ \\
\hline & SEG & $43.22 \pm 13.122$ & $35.22 \pm 11.278$ & -8.00 & 1.99 \\
\hline & $t$-value & 1.77 & -0.52 & \multicolumn{2}{|c|}{ Group $\times$ Time $F(1,17)=5.83 *$} \\
\hline \multirow{3}{*}{$\begin{array}{l}\text { SPPB } \\
\text { (score) }\end{array}$} & OSEG & $6.70 \pm 1.160$ & $12.10 \pm 0.876$ & 5.4 & $-17.68^{* * *}$ \\
\hline & SEG & $8.67 \pm 1.500$ & $12.44 \pm 1.130$ & 3.78 & $-5.89^{* *}$ \\
\hline & $t$-value & $-3.21 * *$ & -0.74 & \multicolumn{2}{|c|}{ Group $\times$ Time $F(1,17)=5.58 *$} \\
\hline
\end{tabular}

Values are reported as mean \pm SD. OSEG, osteoarthritis sarcopenia exercise group; SEG, sarcopenia exercise group; L-TCSA, left thigh muscle cross-sectional area; R-TCSA, right thigh muscle cross-sectional area; WOMAC, The Western Ontario and McMaster Universities Osteoarthritis Index; SPPB, short physical performance battery; SD, standard deviation. ${ }^{*} p<0.05 .{ }^{* *} p<0.01 .{ }^{* *} p<0.001$.

Both the left and right TCSA $\left(\mathrm{cm}^{2}\right)$ increased after exercise in both groups. In particular, the SEG showed a greater increase in the left TCSA compared to the OSEG, showing a significant group interaction effect $(p<0.01)$. Both groups exhibited enlarged muscle fibers after the exercise.

The Western Ontario and McMaster Universities Osteoarthritis Index (WOMAC), which measures ADL associated with OA, did not change in the SEG but statistically significantly improved after the intervention in the OSEG $(p<0.001)$, showing an interaction effect between the two groups $(p<0.05)$. In particular, OA-related signs were markedly reduced in the OSEG after exercise. Furthermore, the Short Physical Performance Battery (SPPB), which comprehensively assesses ADL, significantly improved after the exercise program in both groups $(p<0.01)$. There was a significant interaction effect, as the exercise program was more effective in the OSEG than in the SEG $(p<0.05)$.

\section{Discussion}

This study investigated the positive effects of exercise in elderly women with sarcopenia and OA by examining changes in their muscle cross-sectional surface area and physiological parameters, such as blood markers related to myokines, after the exercise intervention.

In our study, the exercise program significantly increased the levels of IGF-1, irisin, and anti-inflammatory factor IL-10. In contrast, it significantly reduced the Mstn levels, which hinders muscle protein synthesis and the inflammatory marker TNF- $\alpha$. The WOMAC score, which is related to ADL, significantly changed in the OSEG. SPPB improved in both groups after the exercise.

Aging deteriorates physiological functioning and results in physical changes, marked by diminished muscle functioning and physical fitness. One notable problem is the presence of sarcopenia. From a physiological perspective, aging-induced sarcopenia cannot be neglected because it induces systemic inflammation and results in the secretion of various proinflammatory cytokines.

Muscles are enlarged when there is more signaling for muscle protein synthesis than that for protein degradation, and factors that induce muscle enlargement, which are expressed due to positive overload, such as exercise, activate downstream proteins in myocytes via the PI3K/Akt signaling pathway, thereby inducing protein synthesis, and increasing muscle mass [33]. IGF-1 is involved in cellular proliferation and differentiation, and thus plays an important role in regulating metabolism and growth of tissues, such as muscles, cartilage, and bone, and IGF-1 concentration in the blood and muscles is reduced with aging-related muscle loss [34]. 
The moderate-intensity exercise used in this study had significant effects on blood myokine concentrations, such as IGF-1, irisin, and IL-10. Muscle training increases the frequency and amount of growth hormone secretion, which in turn promotes the expression of IGF-1 and induces myocyte growth and enlargement, thereby increasing muscle mass and strength [35]. This is in line with previous findings indicating that protein synthesis strengthens the muscular cross-sectional area and musculoskeletal structures and contributes to the activation of the energy system and neural transmission [36].

Mstn is a blood marker associated with the inhibition of muscle growth. Mstn is a member of the TGF- $\beta$ superfamily, and it acts directly on myocytes to inhibit myogenesis and differentiation of myocytes [8]. Miyake et al. [37] reported that engaging in $30 \mathrm{~min}$ of exercise every day for 10 days increased muscle mass and reduced Mstn expression. High-intensity resistance exercise, which is effective for muscle growth has been reported to reduce Mstn expression [38].

In this study, both groups showed reduced Mstn levels after exercise, with a greater reduction in OSEG. Furthermore, TNF- $\alpha$, an inflammatory marker that hinders muscle protein synthesis, was also significantly decreased. Both groups showed improvements in TCSA after 15 weeks of exercise compared to baseline. Irisin is a hormone released by myocytes that plays an important role in muscle growth by regulating the balance between exercise and metabolic homeostasis, and its levels in the body are positively correlated with engagement in exercise and intensity of exercise [8,39]. Tsuchiya et al. [40] reported that high-intensity exercise increased irisin levels in the blood. This is in line with our results, where both groups showed significant increases in irisin levels and significant reductions in Mstn levels.

Myokines, which are expressed in skeletal muscles during muscular contractions, are known to directly affect muscle cells (autocrine effect), surrounding tissues (paracrine effect), or other tissues through the blood (endocrine effect) as proteins and hormones released from muscle fibers [41,42].

IL-10 secreted in the muscles is a classic anti-inflammatory cytokine that inhibits immune and inflammatory responses; it is released from T-helper cells, monocytes, and macrophages and regulates anti-inflammatory reactions and neutrophils activitys. Moreover, IL-10 is known to inhibit TNF- $\alpha$-induced inflammatory responses in monocytes [43]. IL-10 rapidly increases in the plasma during exercise, and the positive correlation with exercise intensity clearly suggests that aerobic-anaerobic combined exercise increases the expression of myokines through various physiological mechanisms and supports the spike of myokine expression during high-intensity aerobic exercise and resistance exercise. Inflammatory markers that predict the risk of OA include C-reactive protein (CRP), IL-6, and TNF- $\alpha$, and when inflammation is induced, proinflammatory cytokines derived from monocytes, macrophages, and adipocytes facilitate the reaction [44]. The systemic inflammatory response induced by muscle loss, in turn serves as a cause of $\mathrm{OA}$ as proposed by Benatti et al. [45], and IL-10 is an important anti-inflammatory myokine to be analyzed in this context.

Furthermore, TNF- $\alpha$ is a marker related to adipocytes, and it is not only involved in the progression of OA but also influences the immune system [46]. However, reducing body weight and body fat through regular exercise decreases TNF- $\alpha$ concentration and enhances inflammation and insulin sensitivity, thereby lowering the risk of cardiovascular disease and metabolic disorders [47]. There are varying reports on the effects of exercise on TNF- $\alpha$ levels. While some studies have reported that moderate-intensity exercise either reduced TNF- $\alpha$ concentrations or did not lead to any changes [48], other studies have reported that high-intensity exercise increased TNF- $\alpha$ concentration [49]. In addition, a study that examined the effects of 7 months of jogging, walking, stretching, jump rope, and cycling in obese women reported that their TNF- $\alpha$ concentration significantly declined [50]. Another study reported that regular exercise decreased proinflammatory cytokines, and that 6 months of moderate-intensity exercise decreased TNF- $\alpha$ concentration in patients with insulin resistance [51]. 
In our study, IL-10 expression induced via TNF- $\alpha$ stimulation was significantly improved after exercise in both groups. In particular, post-exercise expression of proinflammatory and anti-inflammatory cytokines was antagonistic, and there was a significant interaction effect between the two groups. This is consistent with previous findings, and it seems that increased IL-10 concentration induced by exercise continuously inhibited inflammatory factors, such as TNF- $\alpha$, in older adults with sarcopenia and OA with high inflammatory markers. In particular, a statistically significant reduction in the group with sarcopenia and OA was observed, which was in line with previous findings indicating that moderate-intensity exercise exerts anti-inflammatory effects by reducing TNF- $\alpha$ [52]; thus, moderate-intensity exercise may be highly effective in older adults. However, establishing the optimal exercise intensity is extremely important, as vigorous exercise can cause inflammatory responses and increase blood TNF- $\alpha$ concentration [49].

Sarcopenia and OA not only cause motor symptoms, such as muscle weakness, pain, and reduced balance, but also hinder basic activities, such as gait, stair climbing, sitting to standing, and turning [53]. Older adults with these conditions have restrictions in their $\mathrm{ADL}$, which in turn deteriorates their quality of life.

In a study on older adults, Stenholm et al. [54] reported that grip strength was significantly reduced in the obesity plus sarcopenia group and the sarcopenia group compared to the normal group among older adults aged 65-79 years and that grip strength was diminished in all older adults aged $\geq 80$ years, regardless of group. Similarly, Chang et al. [7] reported that grip strength was significantly lower in the group with obesity and sarcopenia and in the group with sarcopenia than in the normal group, and that it was the lowest in the group with obesity and sarcopenia. Considering that a similar aging-related inflammatory mechanism is involved in obesity and OA, grip strength measured at baseline among elderly women with an average age of 75 years in this study was low in both the sarcopenia and sarcopenia and OA groups. In other words, while both groups presented significant inflammation at baseline, the sarcopenia and OA group showed an overall improvement in muscle mass, grip strength, and physical functions after the exercise program. These results support the results of many previous studies. In addition, the reduced muscle strength in the sarcopenia group can be partly explained by the results of Deschenes [55] (2004), where the size and number of fast-twitch muscle fibers are reduced in older adults with reduced muscle mass, resulting in reduced muscle strength.

The SPPB was developed in a multi-center study known as the Established Population for Epidemiologic Studies of the Elderly (EPESE) conducted by the National Institute of Aging (NIA) [56]. This tool consists of three categories that are useful and can be easily applied in older adults with sarcopenia and OA. In the present study, we used this tool as a key assessment tool for factors related to ADL. WOMAC significantly changed in the group with sarcopenia and OA, while SPPB improved after exercise in both groups. In particular, the WOMAC score was significantly improved in the OSEG, with significant differences between the two groups. This suggests that aerobic-anaerobic combined exercise may be effective in early OA. In the present study, the WOMAC score was significantly improved after the 15-week combined exercise in both groups.

These results support the effectiveness of the circuit exercise program consisting of aerobic and anaerobic exercises proposed by Takeshima et al. [27] and are in line with the results of Jung et al. [57], in which a 12-week circuit exercise program improved ambulation, balance, and isokinetic muscle function in elderly women with sarcopenia. Further, Gudlaugsson et al. [58] emphasized the importance of a "combined training intervention" based on the results of his study, which showed that endurance performance, such as 6-min walking ability, improved after 6 months of complex exercise in 117 elderly subjects. Thus, a variety of tools should be used to assess older adults' ADL and quality of life. In addition to SPPB, the Instrumental ADLs and Tinetti Performance Oriented Mobility Assessment are appropriate assessment tools for older adults.

The complex exercise program proposed in this study was effective in enhancing biochemical and morphological factors as well as ADL in elderly women with sarcopenia 
accompanied by OA. Thus, the findings of this study provide useful information for elderly women who intend to engage in exercise to prevent sarcopenia. However, since sarcopenia and sarcopenia with OA may be affected by factors other than exercise, qualitative and quantitative follow-up studies on the improvement of muscle function are required

\section{Conclusions}

The 15-week combined exercise program positively changed physiological and morphological factors, such as muscle growth factors and inflammatory factors, and improved the quality of ADL in elderly women with sarcopenia as well as elderly women with sarcopenia accompanied by OA. Thus, exercise programs should be strongly recommended for elderly women to promote healthy and desirable aging.

Author Contributions: Conceptualization, J.P.; methodology, J.P. and J.L.; software, J.B. and J.L.; formal analysis, J.P. and J.B.; investigation, J.P.; resources, J.P.; data curation, J.B., J.L., and J.P.; writingoriginal draft preparation, J.P. and J.L.; writing—review and editing, J.L. and J.P.; visualization, J.P. and J.L.; supervision, J.L. and J.P.; project administration, J.P. and J.L. All authors have read and agreed to the published version of the manuscript.

Funding: This research received no external funding.

Institutional Review Board Statement: The study was conducted according to the guidelines of the Declaration of Helsinki, and approved by the Institutional Review Board of Sunmoon University (SM-201908-045-1 and 4 October 2019).

Informed Consent Statement: Informed consent was obtained from all subjects involved in the study.

Data Availability Statement: The data presented in this study are available on request from the corresponding author. The data are not publicly available due to privacy.

Conflicts of Interest: The authors declare no conflict of interest.

\section{References}

1. Cruz-Jentoft, A.J.; Bahat, G.; Bauer, J.; Boirie, Y.; Bruyère, O.; Cederholm, T.; Cooper, C.; Landi, F.; Rolland, Y.; Sayer, A.A.; et al. Sarcopenia: Revised European consensus on definition and diagnosis. Age Ageing 2019, 48, 16-31. [CrossRef] [PubMed]

2. Budui, S.L.; Rossi, A.P.; Zamboni, M. The pathogenetic bases of sarcopenia. Clin. Cases Miner. Bone Metab. 2015, 12, 22-26. [CrossRef] [PubMed]

3. Rolland, Y.; Czerwinski, S.; Van Kan, G.A.; Morley, J.E.; Cesari, M.; Onder, G.; Woo, J.; Baumgartner, R.; Pillard, F.; Boirie, Y.; et al. Sarcopenia: Its assessment, etiology, pathogenesis, consequences and future perspectives. J. Nutr. Health Aging. 2008, 12, 433-450. [CrossRef] [PubMed]

4. Elkina, Y.; von Haehling, S.; Anker, S.D.; Springer, J. The role of myostatin in muscle wasting: An overview. J. Cachexia Sarcopenia Muscle. 2011, 2, 143-151. [CrossRef]

5. Yarasheski, K.E.; Bhasin, S.; Sinha-Hikim, I.; Pak-Loduca, J.; Gonzalez-Cadavid, N.F. Serum myostatin-immunoreactive protein is increased in 60-92- year old women and men with muscle wasting. J. Nutr. Health Aging 2002, 6, 343-348.

6. White, T.A.; LeBrasseur, N.K. Myostatin and sarcopenia: Opportunities and challenges-A mini-review. Gerontology 2014, 60, 289-293. [CrossRef]

7. Chang, J.S.; Kim, T.H.; Nguyen, T.T.; Park, K.S.; Kim, N.; Kong, I.D. Circulating irisin levels as a predictive biomarker for sarcopenia: A cross-sectional community-based study. Geriatr. Gerontol. Int. 2017, 17, 2266-2273. [CrossRef]

8. Huh, J.Y.; Mougios, V.; Kabasakalis, A.; Fatouros, I.; Siopi, A.; Douroudos, I.I.; Filippaios, A.; Panagiotou, G.; Park, K.H.; Mantzoros, C.S. Exercise-induced irisin secretion is independent of age or fitness level and increased irisin may directly modulate muscle metabolism through AMPK activation. J. Clin. Endocrinol. Metab. 2014, 99, E2154-E2161. [CrossRef]

9. Hayashida, I.; Tanimoto, Y.; Takahashi, Y.; Kusabiraki, T.; Tamaki, J. Correlation between muscle strength and muscle mass, and their association with walking speed, in community-dwelling elderly Japanese individuals. PLoS ONE. 2014, 9, e111810. [CrossRef]

10. Erlich, A.T.; Tryon, L.D.; Crilly, M.J.; Memme, J.M.; Moosavi, Z.S.M.; Oliveira, A.N.; Beyfuss, K.; Hood, D.A. Function of specialized regulatory proteins and signaling pathways in exercise-induced muscle mitochondrial biogenesis. Integr. Med. Res. 2016, 5, 187-197. [CrossRef]

11. Konopka, A.R.; Harber, M.P. Skeletal muscle hypertrophy after aerobic exercise training. Exerc. Sport Sci. Rev. 2014, $42,53-61$. [CrossRef] 
12. Seo, D.Y.; Lee, S.R.; Kim, N.; Ko, K.S.; Rhee, B.D.; Han, J. Age-related changes in skeletal muscle mitochondria: The role of exercise. Integr. Med. Res. 2016, 5, 182-186. [CrossRef]

13. Yan, Z.; Lira, V.A.; Greene, N.P. Exercise training-induced regulation of mitochondrial quality. Exerc. Sport Sci. Rev. 2012, 40, 159-164. [CrossRef]

14. Ko, I.G.; Jeong, J.W.; Kim, Y.H.; Jee, Y.S.; Kim, S.E.; Kim, S.H.; Jin, J.J.; Kim, C.J.; Chung, K.J. Aerobic exercise affects myostatin expression in aged rat skeletal muscles: A possibility of antiaging effects of aerobic exercise related with pelvic floor muscle and urethral rhabdosphincter. Int. Neurourol. J. 2014, 18, 77-85. [CrossRef]

15. Singh, M.A.; Ding, W.; Manfredi, T.J.; Solares, G.S.; O'Neill, E.F.; Clements, K.M.; Ryan, N.D.; Kehayias, J.J.; Fielding, R.A.; Evans, W.J. Insulin-like growth factor of skeletal muscle after weight-lifting exercise in frail elders. Am. J. Physiol. 1999, 277, 135-143. [CrossRef]

16. Kozakowski, J.; Papoerska, L.; Krassowski, J.; Zgliczynski, S. The effect of growth hormone replacement therapy on markers of bone formation and bone mineral density in elderly men. Pol. Arch. Med. Wewn. 1998, 100, 306-312. (In Polish)

17. Kreamer, W.J.; Ratamess, N.A.; French, D.N. Resistance training for health and performance. Curr. Sports Med. Rep. 2002, 1, 165-171. [CrossRef]

18. Roth, S.M.; Martel, G.F.; Ivey, F.M.; Lemmer, J.T.; Tracy, B.L.; Metter, E.J.; Hurley, S.M.; Rogers, M.A. Skeletal muscle satellite cell characteristics in young and older men and women after heavy resistance strength training. J. Gerontol. A Biol. Sci. Med. Sci. 2001, 56, 240-247. [CrossRef]

19. Segal, N.A.; Wallace, R. Tolerance of an aquatic power training program by older adults with symptomatic knee osteoarthritis. Arthritis 2012, 2012, 895495. [CrossRef]

20. Papalia, R.; Zampogna, B.; Torre, G.; Lanotte, A.; Vasta, S.; Albo, E.; Tecame, A.; Denaro, V. Sarcopenia and its relationship with osteoarthritis: Risk factor or direct consequence? Musculoskelet. Surg. 2014, 98, 9-14. [CrossRef]

21. Kemmler, W.; Teschler, M.; Goisser, S.; Bebenek, M.; von Stengel, S.; Bollheimer, L.C.; Sieber, C.C.; Freiberger, E. Prevalence of sarcopenia in Germany and the corresponding effect of osteoarthritis in females 70 years and older living in the community: Results of the FORMoSA study. Clin. Interv. Aging 2015, 10, 1565-1573. [CrossRef]

22. Goldring, M.B.; Otero, M.; Plumb, D.A.; Dragomir, C.; Favero, M.; El Hachem, K.; Hashimoto, K.; Roach, H.I.; Olivotto, E.; Borzì, R.M.; et al. Roles of inflammatory and anabolic cytokines in cartilage metabolism: Signals and multiple effectors converge upon MMP-13 regulation in osteoarthritis. Eur. Cells Mater. 2011, 21, 202-220. [CrossRef]

23. Inglis, J.J.; Nissim, A.; Lees, D.M.; Hunt, S.P.; Chernajovsky, Y.; Kidd, B.L. The differential contribution of tumour necrosis factor to thermal and mechanical hyperalgesia during chronic inflammation. Arthritis Res. Ther. 2005, 7, 807-816. [CrossRef]

24. Helmak, I.C.; Mikkelsen, U.R.; Børglum, J.; Rothe, A.; Petersen, M.C.; Andersen, O.; Langberg, H.; Kjaer, M. Exercise increase interleukin-10 levels both intraarticularly and peri-synovially in patients with knee osteoarthritis: A randomized controlled trial. Arthritis Res. Ther. 2010, 12, 126-136. [CrossRef]

25. Johnston, A.P.; De Lisio, M.; Parise, G. Resistance training, sarcopenia, and the mitochondrial theory of aging. Appl. Physiol. Nutr. Metab. 2008, 33, 191-199. [CrossRef]

26. Heo, J.W.; No, M.H.; Park, D.H.; Kang, J.H.; Kwak, H.B. Aging-induced sarcopenia and exercise. Asian J. Kinesiol. 2017, 19, 43-59.

27. Takeshima, N.; Rogers, M.E.; Islam, M.M.; Yamauchi, T.; Watanabe, E.; Okada, A. Effect of concurrent aerobic and resistance circuit exercise training on fitness in older adults. Eur. J. Appl. Physiol. 2004, 93, 173-182. [CrossRef]

28. Roberts, H.C.; Denison, H.J.; Martin, H.J.; Patel, H.P.; Syddall, H.; Cooper, C.; Sayer, A.A. A review of the measurement of grip strength in clinical and epidemiological studies: Towards a standardised approach. Age Ageing 2011, 40, 423-429. [CrossRef]

29. Leenders, M.; Verdijk, L.B.; van der Hoeven, L.; van Kranenburg, J.; Nilwik, R.; van Loon, L.J. Elderly men and women benefit equally from prolonged resistance-type exercise training. J. Gerontol. A Biol. Sci. Med. Sci. 2013, 68, 769-779. [CrossRef]

30. Goodpaster, B.H.; Thaete, F.L.; Kelley, D.E. Composition of skeletal muscle evaluated with computed tomography. Ann. N. Y. Acad. Sci. 2000, 904, 18-24. [CrossRef]

31. Strandberg, S.; Wretling, M.L.; Wredmark, T.; Shalabi, A. Reliability of computed tomography measurements in assessment of thigh muscle cross-sectional area and attenuation. BMC Med. Imaging 2010, 10, 18. [CrossRef] [PubMed]

32. Park, J.Y.; Song, Y.J. Effects of 15-week complex exercise program of sarcopenia elderly women on body composition, IGF-1 and hip muscle strength. Korean J. Sport 2020, 18, 621-633. [CrossRef]

33. Bodine, S.C.; Stitt, T.N.; Gonzalez, M.; Kline, W.O.; Stover, G.L.; Bauerlein, R.; Zlotchenko, E.; Scrimgeour, A.; Lawrence, J.C.; Glass, D.J.; et al. Akt/mTOR pathway is a crucial regulator of skeletal muscle hypertrophy and canprevent-74-muscle atrophy in vivo. Nat. Cell Biol. 2001, 3, 1014-1019. [CrossRef] [PubMed]

34. Morley, J.E. Hormones and sarcopenia. Curr. Pharm. Des. 2017, 23, 4484-4492. [CrossRef]

35. Singh, N.A.; Stavrinos, T.M.; Scarbek, Y.; Galambos, G.; Liber, C.; Singh, M.A.F. A randomized controlled trial of high versus low intensity weight training versus general practitioner care for clinical depression in older adults. J. Gerontol. A Biol. Sci. Med. Sci. 2005, 60, 768-776. [CrossRef]

36. McCall, G.E.; Byrnes, W.C.; Fleck, S.J.; Dickinson, A.; Kraemer, W.J. Acute and chronic hormonalresponses to resistance training designed to promote muscle hypertrophy. Can. J. Appl. Physiol. 1999, 24, 96-107. [CrossRef]

37. Miyake, M.; Takahashi, H.; Kitagawa, E.; Watanabe, H.; Sakurada, T.; Aso, H.; Yamaguchi, T. AMPK activation by AICAR inhibits myogenic differentiation and myostatin expression in cattle. Cell Tissue Res 2012, 349, 615-623. [CrossRef] 
38. Oksbjerg, N.; Gondret, F.; Vestergaard, M. Basic principles of muscle development and growth in meat-producing mammals as affected by the insulin-like growth factor (IGF) system. Domest. Anim. Endocrinol. 2004, 27, 219-240. [CrossRef]

39. Lecker, S.H.; Zavin, A.; Cao, P.; Arena, R.; Allsup, K.; Daniels, K.M.; Joseph, J.; Schulze, P.C.; Forman, D.E. Expression of the irisin precursor FNDC5 in skeletal muscle correlates with aerobic exercise performance in patients with heart failure. Circ. Heart Fail. 2012, 5, 812-818. [CrossRef]

40. Tsuchiya, Y.; Ando, D.; Goto, K.; Kiuchi, M.; Yamakita, M.; Koyama, K. High intensity exercise causes greater irisin response compared with lowintensity exercise under similar energy consumption. Tohoku J. Exp. Med. 2014, 233, 135-140. [CrossRef]

41. Pedersen, B.K.; Akerstrom, T.C.; Nielsen, A.R.; Fischer, C.P. Role of myokines in exercise and metabolism. J. Appl. Physiol. 2007, 103, 1093-1098. [CrossRef]

42. Gonzalez-Cadavid, N.F.; Taylor, W.E.; Yarasheski, K.; Sinha-Hikim, I.; Ma, K.; Ezzat, S.; Shen, R.; Lalani, R.; Asa, S.; Mamita, M.; et al. Organization of the human myostatin gene and expression in healthy men and HIV-infected men with muscle wasting. Proc. Natl. Acad. Sci. USA 1998, 95, 14938-14943. [CrossRef]

43. Cassatella, M.A. The neutrophil: One of the cellular targets of interleukin-10. Int. J. Clin. Lab. Res. 1998, 28, 148-161. [CrossRef]

44. Jialal, I.; Devaraj, S. Inflammation, and atherosclerosis. The value of the high senstive C-reactive protein assay as a marker. Am. J. Clin. Pathol. 2001, 116, S108-S115.

45. Benatti, F.B.; Pedersen, B.K. Exercise as an anti-inflammatory therapy for rheumatic diseases-Myokine regulation. Nat. Rev. Rheumatol. 2014, 11, 86-97. [CrossRef]

46. Packard, R.R.; Libby, P. Inflammation in atherosclerosis: From vascular biology to biomarker discovery and risk predictionatherosclerosis: From vascular biology to biomarker discovery and risk prediction. Clin. Chem. 2008, 54, 24-38. [CrossRef]

47. Fischer, C.P.; Berntsen, A.; Perstrup, L.B.; Eskildsen, P.; Pedersen, B.K. Plasma levels of interleukin-6 and C-reactive protein are associated with physical inactivity independent of obesity. Scand. J. Med. Sci. Sports 2007, 17, 580-587. [CrossRef]

48. Drenth, J.P.; Krebber, T.J.; Bijzet; Van Der, M.J.W. Increased circulating cytokine receptor antagonist and exvivo interleukin-1 receptor antagonist and interleukin1 beta production but decreased tumour necrosis factor-alpha production after a $5-\mathrm{km}$ run. Eur. J. Clin. Investig. 1998, 28, 866-872. [CrossRef]

49. Pederson, B.K.; Steensberg, A.; Fischer, C.; Keller, C.; Ostrowski, K.; Schjerling, P. Exercise and cytokines with particular on muscle-derived IL-6. Exerc. Immunol. Rev. 2001, 7, 18-31.

50. Kondo, T.; Kobayashi, I.; Murakami, M. Effect of exercise on circulating adipokine levels in obese young women. Endocr. J. 2006, 53, 189-195. [CrossRef]

51. Monzillo, L.U.; Hamdy, O.; Horton, E.S.; Ledbury, S.; Mullooly, C.; Jarema, C.; Porter, S.; Ovalle, K.; Moussa, A.; Mantzoros, C.S. Effect of lifestyle modification on adipokine levels in obese subjects with insulin resistance. Obes. Res. 2003, 11, 1048-1054. [CrossRef]

52. Geffken, D.F.; Cushman, M.; Burke, G.L.; Polak, J.F.; Sakkinen, P.A.; Tracy, R.P. Association between physical activity and markers of inflammation in a healthy elderly population. Am. J. Epidemiol. 2001, 153, 242-250. [CrossRef]

53. Sharp, S.A.; Brouwer, B.J. Isokinetic strength training of the hemiparetic knee: Effects on function and spasticity. Arch. Phys. Med. Rehabil. 1997, 78, 1231-1236. [CrossRef]

54. Stenholm, S.; Alley, D.; Bandinelli, S.; Griswold, M.E.; Koskinen, S.; Rantanen, T.; Guralnik, J.M.; Ferrucci, L. The effect of obesity combined with low muscle strength on decline in mobility in older persons: Results from the InCHIANTI study. Int. J. Obes. 2009, 33, 635-644. [CrossRef] [PubMed]

55. Deschenes, M.R. Effects of aging on muscle fibre type and size. Sports Med. 2004, 34, 809-824. [CrossRef] [PubMed]

56. Guralnik, J.M.; Simonsick, E.M.; Ferrucci, L.; Glynn, R.J.; Berkman, L.F.; Blazer, D.G.; Scherr, P.A.; Wallace, R.B. A short physical performance battery assessing lower extremity function: Associations with selfreported disability and prediction of mortality. $J$. Gerontal. 1994, 49, M85-M94. [CrossRef] [PubMed]

57. Jung, W.S.; Kim, Y.Y.; Park, H.Y. Circuit Training training iImprovements in Korean wWomen with sSarcopenia. Percept. Mot. Skills 2019, 126, 828-842. [CrossRef]

58. Gudlaugsson, J.; Aspelund, T.; Gudnason, V.; Olafsdottir, A.S.; Jonsson, P.V.; Arngrimsson, S.A.; Johannsson, E. The effects of 6 months' multimodal training on functional performance, strength, endurance, and body mass index of older individuals. Are the benefits of training similar among women and men? Laeknabladid 2013, 99, 331-337. [PubMed] 